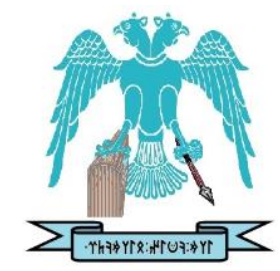

JOURNAL OF ENERGY SYSTEMS

$2021,5(2)$

\title{
Is exergy destruction minimization the same thing as energy efficiency maximization?
}

\author{
Birol Kilkis \\ EU Renewable Heating and Cooling (RHC) \\ OSTIM Technical University Ankara Turkey \\ Polar Teknoloji, Ankara Turkey, birolkilkis@ hotmail.com
}

\begin{abstract}
This paper discusses whether the exergy destruction minimization or energy efficiency maximization comes first in resolving the climate emergency problem and provides sustainable solution options regarding the $2^{\text {nd }}$ Law of thermodynamics. It has been shown that low-temperature district energy systems with renewable energy sources and waste heat are effective in minimizing exergy destructions, while energy efficiency has a secondary impact. The research has been based on the Rational Exergy Management Model. The corresponding rational exergy management efficiency was directly related to nearly-avoidable $\mathrm{CO}_{2}$ emissions responsibility with a global magnitude of around $80 \%$ of direct emissions in the built environment. One conclusion deduced from such an unrecognized magnitude so far is that nearly-avoidable $\mathrm{CO}_{2}$ emissions may not be ignored anymore to develop new strategies for sustainable decarbonization, while the $1^{\text {st }}$ Law measures have limited remaining capabilities. New equations were developed to show the impact of exergy destructions on total $\mathrm{CO}_{2}$ emissions. Sample results show that a 30 percent-point decrease of exergy destructions comparing to the supplied exergy in thermo-mechanical systems has the potential of reducing total $\mathrm{CO}_{2}$ emissions by $35 \%$. The paper argues that current exergy destruction is around 0.8 of the supply exergy, as an industry average, which gives ample room for improvement using the $2^{\text {nd }}$ Law, while the $1^{\text {st }}$ Law efficiency is already higher, and there is less room available for improvements concerning $\mathrm{CO}_{2}$ emissions. The paper shows that the $1^{\text {st }}$ Law efficiency may be increased by about 0.15 points, which gives a window of opportunity about a 25 percent-point decrease in emissions. The second main conclusion is that nowadays, new decarbonization strategies are needed based on the $2^{\text {nd }}$ Law, which will positively impact when coupled with the current $1^{\text {st }}$ Law measures towards meeting the Paris agreement.
\end{abstract}

Keywords: Energy efficiency, Exergy destruction, Low-temperature applications

Cite this paper as:

Kilkis, B. Is exergy destruction minimization the same thing as energy efficiency maximization? Journal of Energy Systems 2021, 5(2), 165-184, DOI: 10.30521/jes.938504

(C) 2021 Published by peer-reviewed open access scientific journal, JES at DergiPark (https://dergipark.org.tr/en/pub/jes) 


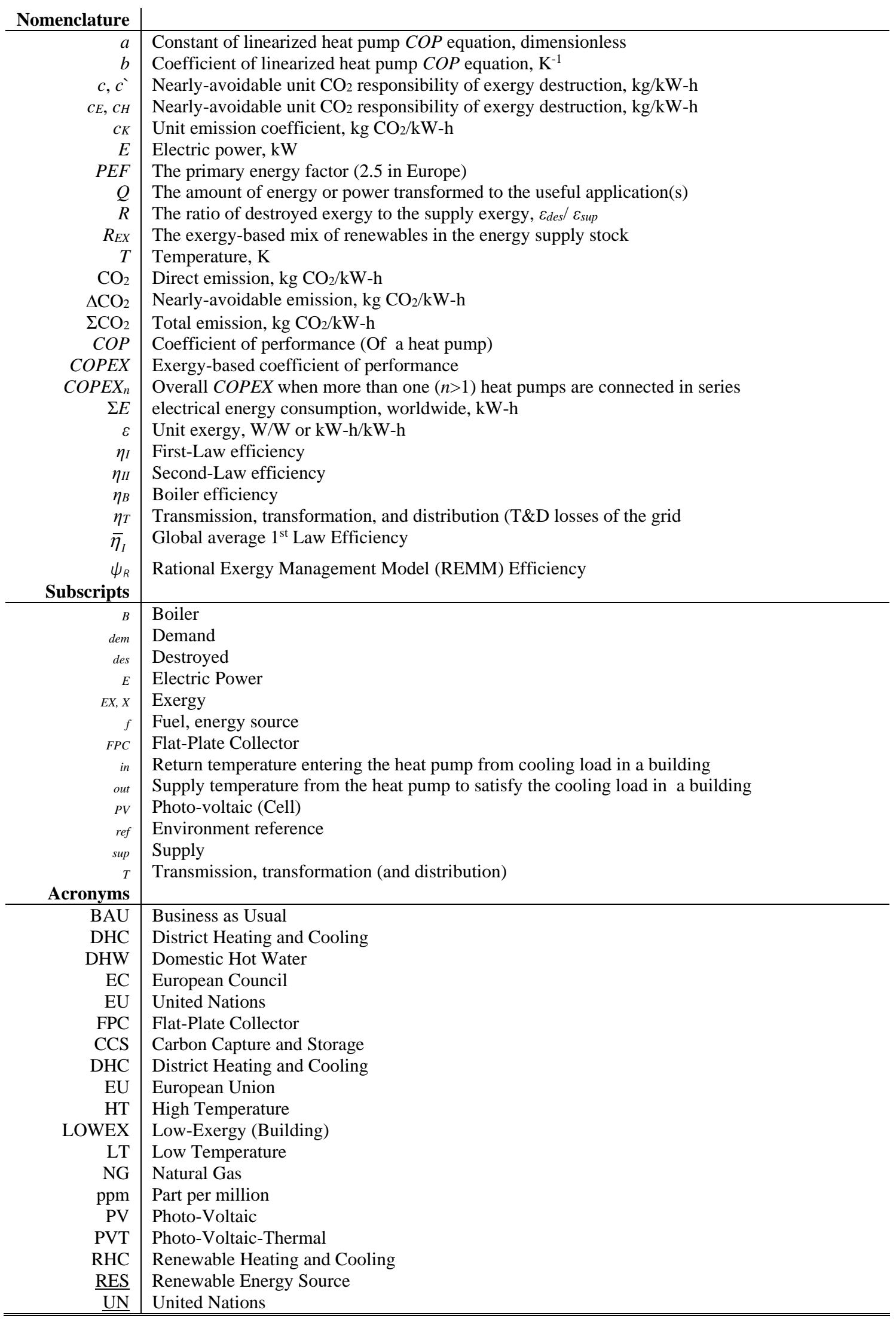




\section{INTRODUCTION}

As of November 19, 2020, remarks of the UN Secretary-General on Climate Action to the European Council on Foreign Relations officially elevated the global warming issue to the global emergency status, of which 38 countries have already ratified [1]. In quote: "It is essential that the European Union commits to reducing emissions by at least 55 percent by 2030. The Climate Ambition Summit on the fifth anniversary of the Paris Agreement represents a clear opportunity for the EU to present its more ambitious climate plan" [1].

At the Climate Ambition Summit, Antonio Guterres said that more must be done to hit net-zero emissions [2]. His expression, in the quote, 'something must be done' is very important because the global warming and $\mathrm{CO}_{2}$ content in the atmosphere are well measured and documented. However, today`s decarbonization measures fall short because the $1^{\text {st }}$ Law of Thermodynamics limits the ability to see the solution's entirety in terms of the quality of energy. A much more sustainable set of potentially effective measures are hidden in the $2^{\text {nd }}$ Law of Thermodynamics. In other words, more has to be done may but into action if and only if the technical, scientific, political, and intergovernmental awareness is raised with the $2^{\text {nd }}$ Law. The $2^{\text {nd }}$ Law deals with the quality (Useful work potential) of energy rather than the quantity of energy that the $1^{\text {st }}$ Law deals with. If the qualities of energy supply and demand are not properly matched, some of the quality of supplied energy (exergy) will be irreversibly destroyed, causing additional $\mathrm{CO}_{2}$ emissions.

The goals and methods for achieving 100\% renewable energy cities and communities, mainly in terms of renewable heating and cooling [3], involve innovative solutions with a better understanding of the fundamental theory, which covers a broad chain of low-enthalpy renewable and waste energy sources, distribution technologies, and rational utilization of energy and power at the final consumption points. Solar energy is not an exception and is indeed a very important component of holistic circularity, provided that it is not limited to economics and quantity of energy [4]. To realize the EU 2050 decarbonization roadmap, EC has identified four implementation fields. One of them is solar. The other three are geothermal, biomass, and cross-cutting fields [5]. According to the European Council [6], sector integration for a circularity offers significant opportunities for wider utilization of renewables and decarbonization along with the new Circular Economy Action Plan [7].

This goal may be realized by establishing strong synergies between electricity power, gas, heat, and cold networks. However, this brings a new problem that has been ignored before. This problem requires a new balancing format among various qualities of different energy supplies and demand, all of which have different unit exergy. In other words, such a circularity elevates the importance of the quality management of energy above quantity management. EC reports only address the economy in energy quantity format and ignore the energy quality [8]. For example, EU strategists offer decarbonization by total electrification using heat pumps, which operate on green electricity [9]. According to many strategists, total electrification may seem to be a perfect solution for the quantity management of energy ( $1^{\text {st }}$ Law of Thermodynamics). One of the four key cross-cutting energy technologies identified by Science Europe or applications is heat pumps with green electricity [5]. However, even if a 100\% renewable energy system generates the power to operate the vapor compression heat pumps, the exergy (Quality) of electricity is higher than the quality of thermal energy generated by pumps (Heating or cooling). This difference renders an exergy deficit, which causes additional $\mathrm{CO}_{2}$ emissions, even though renewables generate electricity. This deficit shows that $100 \%$ renewables on the energy generation side do not guarantee nearly zero carbon applications in the global energy and environment stock. In this respect, green solar energy must stay green by utilizing it in the least exergy-destroying applications in a good balance between the supply and demand exergy. Fig. 1 shows a projection about consumption scenarios until 2040 [10]. There are two alternative predictions for 2040, namely 50\% RHC and 100\% RHC. According to this scenario, the major component of heating and cooling by non-RES sources will diminish to zero in the $100 \%$ 
RHC scenario in 2040, by definition. All these predictions are based on the $1^{\text {st }}$ Law of thermodynamics. Consider a house with PV panels, which contributes to the $100 \%$ RHC target.

PV panels miss the opportunity of generating collocated heat that a PVT system could do. Therefore, an additional roof area is needed for installing flat plate solar hot water collectors. This time they will miss the opportunity of generating solar power. According to the $2^{\text {nd }}$ Law, missed opportunities mean irreversible destructions of the quality of solar energy (Exergy). These destructions are responsible for indirect $\mathrm{CO}_{2}$ emissions. Although a PVT array seems to solve the problem largely, it was shown by Kilkis, B. [11] that there will always be exergy destructions. Mathematically speaking, an absolute $100 \%$ renewable RHC target will not be possible due to the diminishing nature of solar equipment embodiments with traces of fossil fuels to be spent for the next steps for achieving $100 \%$ RHC $[4,12]$. E-gas and hydrogen, shown in Fig. 2, are derivatives of solar and wind energy sources. Therefore, they may be included in a broader solar and wind energy spectrum. E-gas will not be a complete solution either [13]. Kilkis [12] has further shown that without the $2^{\text {nd }}$ Law, despite seeing and measuring global warming, almost half of the real and sustainable decarbonization opportunities will remain missing because exergy destructions causing additional $\mathrm{CO}_{2}$ emission responsibilities are not recognized. In other words, we are aware of the global warming problem, but we are aware of only half of the potential solutions. Nevertheless, many scientists and engineers insist that the 1st Law is sufficient for solving the entire problem because the $2^{\text {nd }}$ Law gives give similar solutions. The following section is an answer to such statements.

According to Tanay, S. U. [14], the cause of the coronavirus epidemic cannot be disassociated from the consequences of the climate crisis. Activities to revert the climate crisis, however, seem to be insufficient, and atmospheric $\mathrm{CO}_{2}$ concentration seems to increase despite the introduction of new and widely implemented green systems, carbon capture, and storage (CCS) (Fig. 3). The best measure against climate emergency that has been conceived so far, the Greener Growth +CCS target, might only stabilize the $\mathrm{CO}_{2}$ content to $450 \mathrm{ppm}$ by 2050 , which is far beyond the target of the Paris Agreement. Fig. 3 is a revelation that the previous work that has been carried out and the future attempts on green transition for achieving the targets of the Paris Agreement have been and will be necessary but not sufficient measures, like in terms of EU 20-20-20 strategy (20\% Energy Savings, $20 \%$ Use of Renewables, and 20\% Increase in Energy Efficiency), and despite great interest in solar energy, wind, and geothermal. A fundamentally missing point in these efforts has been the ignorance of the $2^{\text {nd }}$ Law of Thermodynamics, which deals with the quality of energy sources and demand.

In this respect, all energy sources are not created equal. Each of them has a different useful work potential (exergy), and they must be matched with demands with similar exergy. Otherwise, exergy mismatches result in nearly-avoidable $\mathrm{CO}_{2}$ emissions (by minimizing exergy mismatches). There are few studies about exergy analysis like in low-temperature, renewable district energy systems. Falk, P. M. [15], a member of Annex 64, has focused on exergy principles of district energy optimization. The EU parliament has already been alerted about the immediate essence of the $2^{\text {nd }}$ Law. Kilkis [16] has proposed transformation tools to transition several EU guides and directives from the $1^{\text {st }}$ Law base to the $2^{\text {nd }}$ Law base. Science Europe Scientists have also issued a brochure on the critical contribution potential of exergy analysis [8]. Modeling results [17] predict that current regulations based on the $1^{\text {st }}$ Law only may reduce $\mathrm{CO}_{2}$ emissions up to $49.0 \pm 2.9 \%$ and increase the efficiency from $10.7 \%$ to $13.7 \%$. According to the same study, however, low-exergy solutions with renewable electricity and heat pumps can reduce carbon emissions by $88.2 \pm 2.4 \%$, achieving a sectoral exergy efficiency of $19.8 \%$. Their results still ignore the nearly-avoidable $\square \mathrm{CO}_{2}$ emissions component of the total emissions responsibility. The nearly-avoidable $\square \mathrm{CO}_{2}$ emissions result from exergy destructions taking place according to the imbalance of unit exergy between electricity that heat pumps use and the heating or cooling unit exergy provided by heat pumps unless their $C O P$ in heating is unattainably very high (in the order of 15) unless they are cascaded into smaller heat pumps in tandem. Nevertheless, their predictions indicate the right direction and essence that exergetic approach is the ultimate step for sustainable decarbonization. 


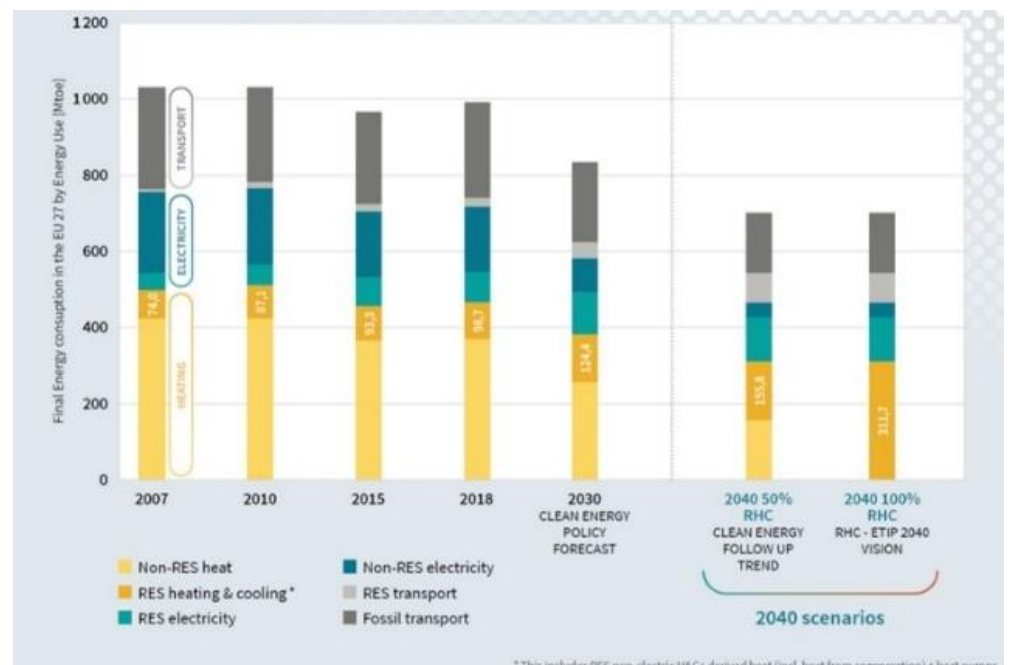

Figure 1. 2007-2040 Final Energy Consumption Scenarios in the EU 27 Countries and Their Origin RES Included [10].

Solar heating and cooling call for low-temperature (LT) district energy systems, especially in 5DE district energy systems. This requirement compounds the current problem of the primary energy factor, $P E F$, in the building sector. For example, it is 2.3 , following the commercial sector (2.7) in the USA. Overall, $P E F$ is 2.5 in the EU Countries. These figures mean that buildings consume about 2.3 times more energy than in-house spending [18]. Therefore, district energy systems must minimize this ratio in heat and cold distribution/collection. In this quest, exergy considerations become more critical in low-temperature applications.

This research aims to bring new design and evaluation metrics and optimum design tools using the $2^{\text {nd }}$ Law of thermodynamics and identify two major $\mathrm{CO}_{2}$ emission components. The first component is the direct $\mathrm{CO}_{2}$ emissions and can be simply calculated from the $1^{\text {st }}$ Law if fossil fuels are used. This component is the direct emissions (onsite), which can be measured and observed directly. However, this component alone is not explaining the higher $\mathrm{CO}_{2}$ emissions on a global scale and the current global $\mathrm{CO}_{2}$ concentration measurements in the atmosphere. There must be a second component, which is for the first time explained for the first time and related to exergy destructions that may only be determined from the $2^{\text {nd }}$ Law. This approach is the major originality of the research. The first step is to directly relate the so-called nearly-avoidable $\mathrm{CO}_{2}$ emissions, $\square \mathrm{CO}_{2}$, to the exergy destructions, which occur even in apparently $100 \%$ renewable systems and equipment. Two cases are given below, namely solar PV and solar water heater. The next step is to demonstrate the total $\mathrm{CO}_{2}$ emissions responsibility (sum of the two emissions components) of solar systems, as examples, versus fossil fuel systems (natural gas), and lastly, to show how the decarbonization roadmaps should be designed to cover the total emissions to meet the Paris agreement. 


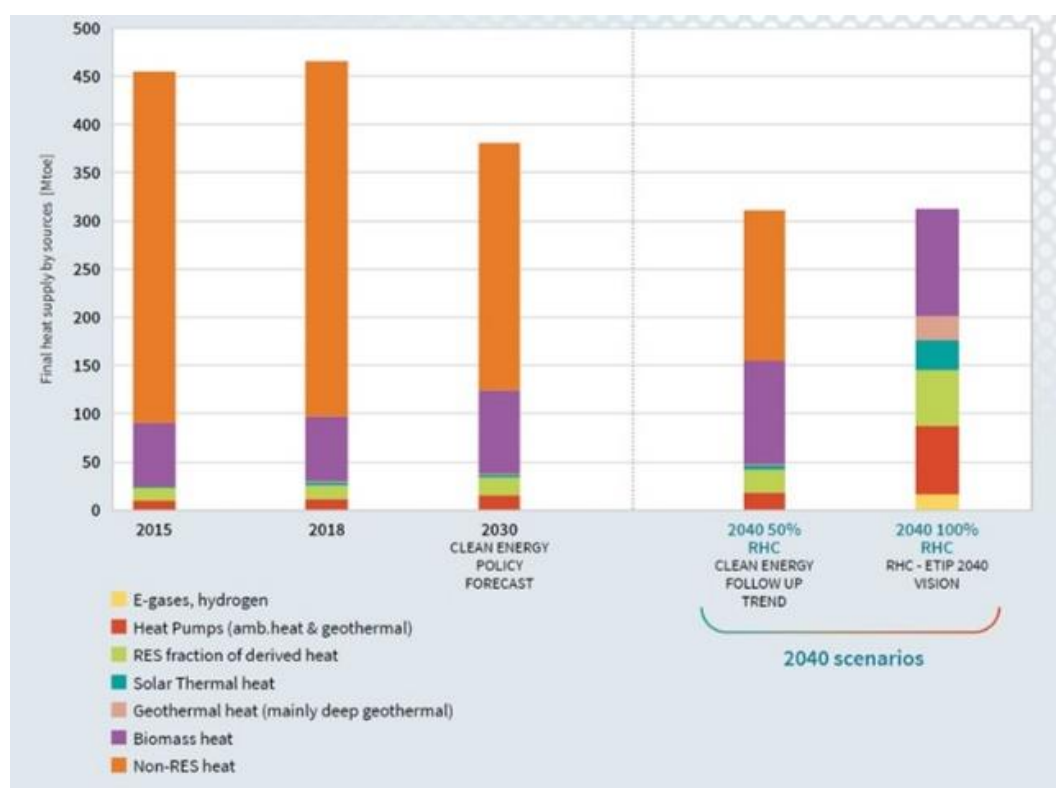

Figure 2. Thermal Power Generation by Sources and Uses. Data extracted on 20/06/2020 21:29:37 from (ESTAT) Dataset: Final energy consumption by-product [TEN00123] Last updated: 06/06/2020 23:00. RES fraction of derived heat refers to heat by cogeneration from renewable electricity (e.g., bioenergy electricity plant that cogenerates heat for a DHC network)

However, the most common argument made by the exergy-skeptics and opponents is the following claim:

Claim: Because the exergy destruction minimization is the same as energy efficiency maximization, exergy analysis is unnecessary but redundant.

Response: Assume that energy supply (In this case solar energy) with an identical amount of $Q_{\text {sup }}$ is utilized in two different applications at the same reference temperature, $T_{r e f}, 283 \mathrm{~K}$, or $287 \mathrm{~K}$ (Williams, M., 2015: Average surface temperature of the World).

Case 1 generates only electrical energy at an efficiency of $\eta_{P V}$ by using part of the solar energy input in an amount of $Q_{E}$. The remaining energy $\left(Q_{s u p}-Q_{E}\right)$ in the form of heat is rejected at a temperature of $T_{E}$. This case destroys exergy downstream by a unit amount of $\varepsilon_{d e s}$ in terms of useful thermal energy potential. This case is typical for solar photovoltaic applications.

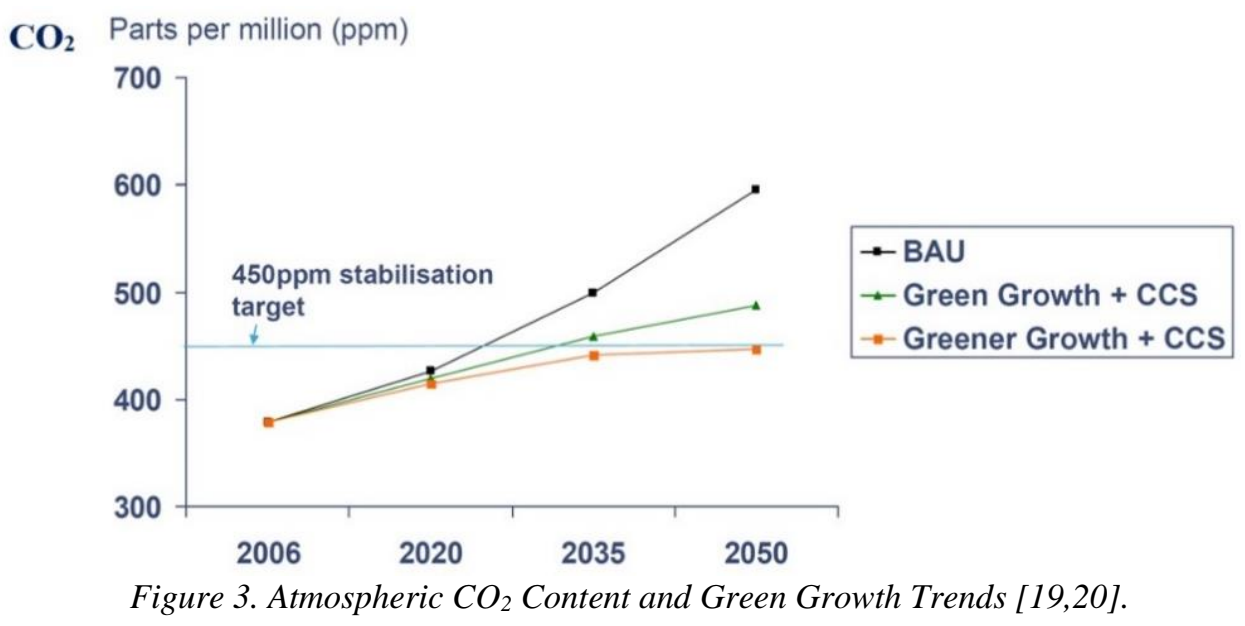

Case 2 generates only thermal energy at an efficiency of $\eta_{F P C}$ by using the same amount of solar energy, $Q_{E}$., starting this time from $T_{E}$ down towards $T_{r e f}$. Different unit exergy in an amount of $\varepsilon_{d e s} 2$ 
is destroyed in terms of potentially useful electrical energy upstream the thermal energy generation. $T_{f}$ is the energy source temperature (or Carnot cycle-equivalent). This case is typical for solar flatplate collector (FPC) for hot domestic hot water (DHW) generation.

Everything looks the same in terms of energy quantity utilized, $Q_{E}$, as long as it remains the same in any process or design. Let the classical objective be to maximize the efficiency, $\eta_{I}$ according to the $1^{\text {st }}$ Law of Thermodynamics:

$$
\eta_{I}=\frac{Q_{E}}{Q_{S u p}}
$$

$\{$ Maximize $\}(1)$

As a solar energy system, the $1{ }^{\text {st }}$ Law energy efficiencies, $\eta_{I}$ in Equation 1 , are identical for both cases, irrespective of whether heat or power is generated and heat, power, or both opportunities are destroyed upstream or downstream. Furthermore, if the power conversion efficiencies of both power conversions are considered, the PV efficiency (about 0.20) is much lower than the FPC efficiency (about 70\%). There is a dilemma of system efficiency and conversion efficiency, which the 1st Law cannot resolve. Fig. 4 shows this dilemma. In other words, two solar power conversion applications have different efficiency, but the solar system efficiency (Equation 1) is the same. Furthermore, FPC may appear to be preferable because it has a higher $1^{\text {st }}$ Law efficiency.

Such a preference, of course, does not consider that electricity has much higher unit exergy, $\varepsilon$, meaning more useful work and value-adding potential in the energy and economy domain. The only step that $1^{\text {st }}$ Law can proceed with about the environment is the usual practice of predicting the $\mathrm{CO}_{2}$ emissions reduction potential from the carbon stock in proportion to $Q_{E}$ in both cases. In Equation 2, $R_{E X}$ is the exergy-based mix of renewable energy in the energy stock of a given region concerning $Q_{\text {sup. }} R_{E X}$ is equal to one in solar PV or FPC cases (neglecting different embodiments). In fossil fuel cases, $R_{E X}$ is zero. $P E F$ in EU countries is around 2.5, and $c_{K}$ for both cases may be taken equal to $0.2 \mathrm{~kg} \mathrm{CO} / \mathrm{kW}$-h of $Q_{E}$ (Equivalent to natural gas). Beyond this point of environmental concerns, the $1^{\text {st }}$ Law, for a given energy supply $\left(Q_{s u p}\right)$, does not differentiate between whether electric power, steam, heat, or cold, at any temperature, are generated as long as $Q_{E}$ is the same, although each of them represents different forms of energy with different qualities (Exergy). For example, electric power has unit exergy, $\varepsilon_{E}$ of $0.95 \mathrm{~kW} / \mathrm{kW}$, which means that $95 \%$ of electrical energy may be utilized in value-adding useful work(s). According to the ideal Carnot cycle, thermal power has a much lower $\varepsilon_{H}$ in heating or cooling (See Equation 4). Exergy-based Equation 5, which at this point the $1^{\text {st }}$ Law stops working, shows that exergy destructions for Cases 1 and 2, $\Delta E_{X I}$ and $\Delta E_{X 2}$, respectively, are not equal with different minimum points regarding $T_{E}$ and $T_{f}$. Only the $2^{\text {nd }}$ Law can differentiate between the two sides of Equation 5.

$$
\mathrm{CO}_{2}=c_{K} P E F \cdot Q_{E} \cdot\left(1-R_{E X}\right),\{\text { Case } 1\} ;-\mathrm{CO}_{2}=c_{K} / \eta_{B} Q_{E} \cdot\left(1-R_{E X}\right),\{\text { Case } 2\}
$$

Because these destructions must be offset by the corresponding type of exergies by someone, somewhere, with some technology and sources, $\mathrm{CO}_{2}$ emission responsibilities are also unequal.

$$
\begin{aligned}
& \varepsilon_{H}=\left(1-\frac{T_{r e f}}{T_{E}}\right) \ll \varepsilon_{E} \\
& Q_{E}\left(1-\frac{T_{r e f}}{T_{E}}\right) \neq Q_{E}\left(1-\frac{T_{E}}{T_{f}}\right) \\
& \text { \{Ideal Carnot Cycle\} (4) } \\
& \text { \{Minimize }\}(5) \\
& \underbrace{\Delta E_{x 1}}_{\text {Thermal Energy Destroyed }} \neq \underbrace{\Delta E_{x 2}}_{\text {Electrical Exergy Destroyed }}
\end{aligned}
$$


Case 1: $\Delta \mathrm{CO}_{2}=c \cdot \varepsilon_{\text {desl }}$ \{Thermal power opportunity is destroyed, $c_{H}=0.27$ )

Case 2: $\Delta \mathrm{CO}_{2}=c^{`} \cdot \varepsilon_{d e s 2}$ \{Electrical power opportunity is destroyed, $c_{E}=0.63$ )

Clearly:

$$
0,27\left(1-\frac{\mathrm{T}_{\mathrm{ref}}}{\mathrm{T}_{\mathrm{E}}}\right) \neq 0,63\left(1-\frac{\mathrm{T}_{\mathrm{E}}}{\mathrm{T}_{\mathrm{f}}}\right)
$$

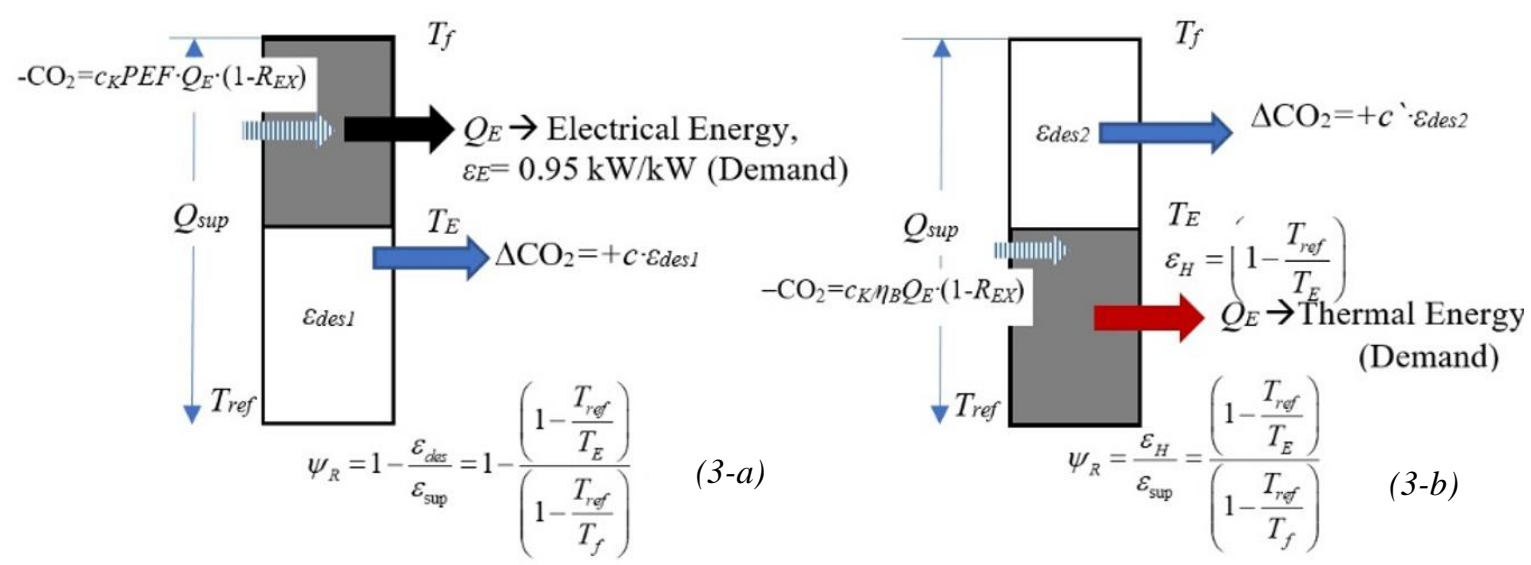

Figure 4. Two different power conversions with the same solar energy with different exergy destructions

The above-mentioned $\Delta \mathrm{CO}_{2}$ terms are nearly avoidable and additional $\mathrm{CO}_{2}$ emissions. The $1^{\text {st }} \mathrm{Law}$ cannot predict $\Delta \mathrm{CO}_{2}$ emissions responsibility at all. Because the $\Delta \mathrm{CO}_{2}$ term is generally in the same order as $\mathrm{CO}_{2}$ emissions, only about half of the global warming sources will remain visible as long as the $2^{\text {nd }} \mathrm{Law}$ is not recognized. Factors $c_{H}$ and $c_{E}$ are the exergy-based unit $\Delta \mathrm{CO}_{2}$ emissions, depending upon the resource mix (Including renewables) for heat and power sectors, respectively. At a reference temperature, $T_{r e f}$ of $283 \mathrm{~K}$, if $T_{E}$ and $T_{f}$ are $400 \mathrm{~K}$ and $620 \mathrm{~K}$, respectively, the left-hand side of Equation 7, which may correspond to PV, will be $0.079 \mathrm{~kg} \mathrm{CO}_{2} / \mathrm{kW}$-h of heat destroyed $\left(\varepsilon_{\text {des }} 1: 0.295\right.$ $\mathrm{kW} / \mathrm{kW}$ ) and the right-hand side, which may correspond to an FPC will be $0.223 \mathrm{~kg} \mathrm{CO} / \mathrm{kW}$-h of power generation opportunity destroyed $\left(\varepsilon_{\text {des } 2}: 0.355 \mathrm{~kW} / \mathrm{kW}\right)$. The inequality ratio is 2.7 .

This example gives a definite answer to the claim: according to Equations 5 and 7, any pair of optimum solutions regarding the $1^{\text {st }}$ and the $2^{\text {nd }}$ Laws for the same problem and their derivatives give different results for minimum exergy destructions-including now $\Delta \mathrm{CO}_{2}$ emissions responsibilitiesversus energy efficiency maximizations. If it is insisted that there is a feasible $T_{E}$ value at which equal solutions are possible, then a simultaneous solution of Equation 7 gives a positive $T^{\top}{ }_{E}$ root of 503.6 $\mathrm{K}\left(230.5^{\circ} \mathrm{C}\right)$. In practice, a PV panel frame may not be as hot as that temperature, and an FPC panel may not be as hot as $503.6 \mathrm{~K}$. So, such practical limits in the field impose additional constraints for equal exergy values for two different systems. The rationality of utilizing solar energy, as defined by Kilkis, S., and Kilkis, B. [21], namely the Rational Exergy Management Efficiency, $\psi_{R}$ are also different as given in Equations 3-a and 3-b:

$$
\psi_{R P V}=1-\frac{\varepsilon_{\text {des }}}{\varepsilon_{\text {sup }}}=1-\varepsilon_{\text {des }} s\left(1-\frac{T_{r e f}}{T_{f}}\right)=1-\frac{0.355}{0.543}=0.346 \quad\{\text { Case } 1, \quad \text { major } \quad \text { exergy } \quad \text { is destroyed }
$$

downstream $\}$

If thermal energy is utilized further down to the reference temperature, which is not possible: 


$$
\psi_{R F P C}<\frac{\varepsilon_{\text {dem }}}{\varepsilon_{\text {sup }}}=\frac{0.292}{0.543}=0.537
$$

\{Case 2, major exergy is destroyed upstream $\}$

If thermal energy is utilized for DHW use only down to $65^{\circ} \mathrm{C}(338 \mathrm{~K})$ against the Legionella risk in open-water circuits, then the solar PV system becomes relatively more rational $\left(\psi_{R P V}=0.346\right)$ :

$$
\psi_{R F P C}=\frac{\varepsilon_{\text {dem }}}{\varepsilon_{\text {sup }}}=\frac{\left(1-\frac{338 \mathrm{~K}}{400 \mathrm{~K}}\right)}{0.543}=\frac{0.155}{0.543}=0.285
$$

These results show that even in a simple solar flat plate collector, the number and type of useful applications arranged in tandem, like further use of the remaining heat in preheating the municipal water supply instead of wasting the heat, is important about exergy-based high rationality. In a holistic view, $\Delta \mathrm{CO}_{2}$ may be related to exergy rationality, $\psi_{R}$. From Equations 6-a and 6-b, and $\psi_{R}$ $\sim \varepsilon_{\mathrm{dem}} / \varepsilon_{\mathrm{des}}$, for all cases, Equation 8 is derived.

$$
\Delta C O_{2} \square \varepsilon_{\text {sup }} c_{E}\left(1-\psi_{R}\right) \text { or } \varepsilon_{\text {sup }} c_{H}\left(1-\psi_{R}\right)
$$

It must also be noted that the PV system generates electric power with unit exergy of $0.95 \mathrm{~kW} / \mathrm{kW}$, while FPC generates only heat by an amount of about $0.155 \mathrm{~kW} / \mathrm{kW}$, meaning that the value-adding potential in the energy budget is comparably small. With the less value-adding potential of FPC systems, more responsibility for $\Delta \mathrm{CO}_{2}$ emissions exists. Such realities may only be revealed by the $2^{\text {nd }}$ Law, such as dedicating available solar surfaces to solar photo-voltaic-heat (PVT) panels, which occupy practically the same solar area but simultaneously generate power and heat, which is a renewable form of cogeneration systems, with less exergy destruction.

All the above discussions and sample calculations show that a new exergy-based, holistic optimization model is necessary to cover a variety of solar systems, equipment, solar-energy derivatives, and exergy-based constraints.

\section{THEORY}

To bring a resolution platform for the dilemma about energy and exergy, especially from the global climate emergency point of view, the total $\mathrm{CO}_{2}$ emissions, which is simply the algebraic sum of the direct and nearly-avoidable emissions, $\Delta \mathrm{CO}_{2}$ due to exergy destructions a combined emissions equation was derived [21].

$$
\sum C O_{2}=\frac{c_{K}}{\bar{\eta}_{I}}\left[1+\left(1-\psi_{R}\right)\right] \sum Q+\frac{c_{K}}{\bar{\eta}_{l} \eta_{T}} \sum E
$$

$\Sigma \mathrm{Q}$ is the heat consumption worldwide, and $\Sigma E$ is the electrical energy consumption worldwide. According to IEA Statistics reproduced in Fig. 5, only $18 \%$ of that total world energy was electricity. Most of the other $82 \%$ was used as heat in districts, industry, and mobility. Assume that transport is a heat engine (except electric mobility) with an efficiency of $35 \%$ on average [22].

$\Sigma E=21 \%$. Assume transport in the form of heat engines, out of which $63 \%$ is from fossil fuels. Assume transport in the form of heat engines. Based on fossil fuels, the emissions are: 


$$
\begin{gathered}
\sum C O_{2}=\frac{c_{K}}{\bar{\eta}_{I}}\left[\left\{1+\left(1-\psi_{R}\right)\right\} 0.79+\frac{1 \times 0.21 \times 0.63}{0.85}\right] \sum Q \\
\sum C O_{2}=\frac{c_{K}}{\bar{\eta}_{I}}\left[0.79+\left(0.79-0.79 \psi_{R}\right)+0.156\right] \sum Q
\end{gathered}
$$

After further simplification,

$$
\sum C O_{2}=\frac{c_{K}}{\bar{\eta}_{I}}\left[1.74-0.79 \psi_{R}\right] \sum Q
$$

$\eta_{T}=0.9, \mathrm{~T} \& \mathrm{D}$ losses is about $10 \%$ today, except less developed countries. Furthermore, assume that $15 \%$ of $Q$ is from renewables.

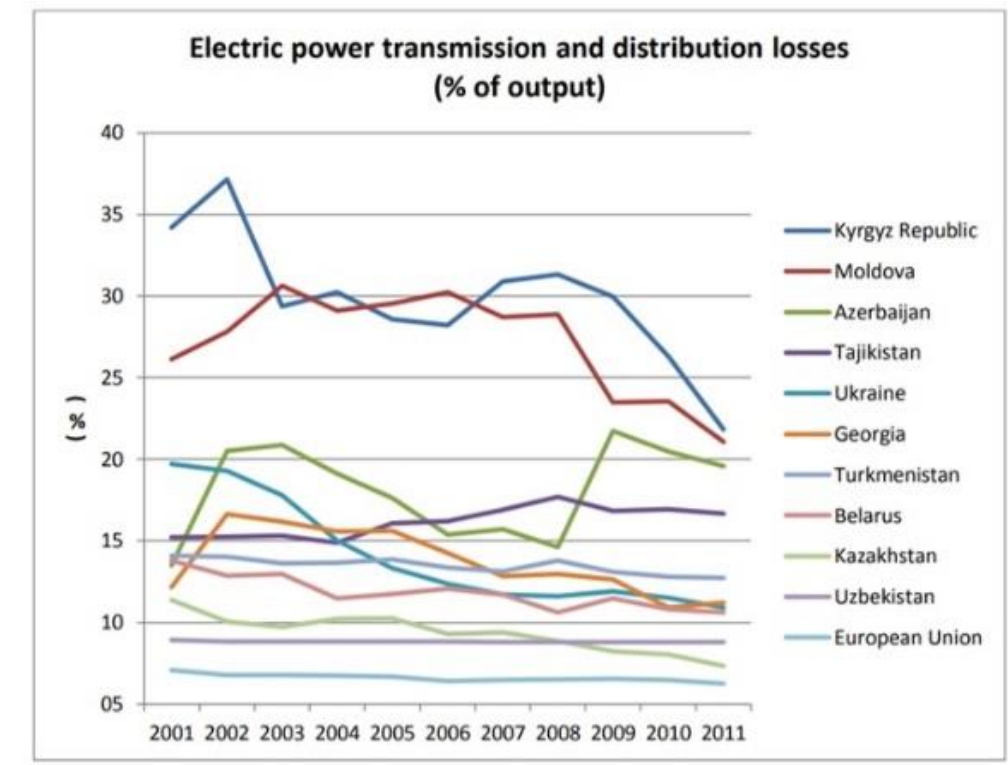

Source: IEA Statistics - Electricity Information (transmission and distribution losses, includes pilferage)

Figure 5. Electric Power T\&D Losses [23].

$$
\frac{\sum C O_{2}}{\sum Q}=\frac{c_{K}}{\bar{\eta}_{I}}\left[1.74-0.79 \psi_{R}\right] \times 0.85 \mathrm{kgCO}_{2} / \mathrm{kW}-\mathrm{h} \text { of heat }
$$

For unit $\mathrm{CO}_{2}$ emissions per $Q$, worldwide, excluding embodied emissions and $\Delta \mathrm{CO}_{2}$, which occur in renewables, as shown in Fig. 4, is given by Eq. 14.

$$
\frac{\sum C O_{2}}{\sum Q}=\frac{c_{K}}{\bar{\eta}_{I}}\left[1.48-0.67 \psi_{R}\right]
$$

Let $R=\frac{\varepsilon_{\text {des }}}{\varepsilon_{\text {sup }}}$, by definition, then:

$$
\psi_{R}=\left(1-\frac{\varepsilon_{\text {des }}}{\varepsilon_{\text {sup }}}\right)=(1-R)
$$




$$
\begin{gathered}
\psi_{R}=\left[1-\frac{\varepsilon_{\text {des }}}{\left|1-\frac{T_{\text {ref }}}{T_{\text {sup }}}\right|}\right]=1-\varepsilon_{\text {des }} \times\left|1-\frac{T_{\text {ref }}}{T_{\text {sup }}}\right|^{-1} \\
\sum \mathrm{CO}_{2}=\frac{c_{K}}{\bar{\eta}_{I}}\left[0.48+\varepsilon_{\text {des }} \times\left|1-\frac{T_{\text {ref }}}{T_{\text {sup }}}\right|^{-1}\right]
\end{gathered}
$$

Today, $R$ is about 0.8 . For green applications, $R$-value must be approximately less than $0.3(1-0.7)$. Now, equation 18 shows the second dilemma about whether maximization of energy or minimization of exergy destructions come first for achieving a sustainable set of measures against climate emergency. In this equation, in a single pass-through transfer of energy, like shown in Fig. 4, the global average $1^{\text {st }}$ Law efficiency may be replaced by the $2^{\text {nd }}$ Law efficiency given in Equation 19. Furthermore, $\varepsilon_{d e s}$ is indexed to the unit supply exergy of natural gas (Heat-based Analysis) with 0.87 W/W (Equation 20).

$$
\begin{gathered}
\eta_{I I}=\frac{0.06 T_{\text {sup }}}{\left(T_{\text {sup }}-T_{\text {ref }}\right)}\left\{T_{\text {ref }}=283 \mathrm{~K}\right\} \\
\varepsilon_{\text {des }}=1-\eta_{I I} \\
\sum \mathrm{CO}_{2}=\frac{c_{K}}{\bar{\eta}_{I I}}\left[0.48+0.87 R \times\left|1-\frac{T_{\text {ref }}}{T_{\text {sup }}}\right|^{-1}\right]\left\{T_{\text {sup }}>T_{\text {ref }} \text { in heating }\right\}
\end{gathered}
$$

Efficiency must be maximized but, in many sectors, it is already high. The function is inverse hyperbolic. Destruction must be minimized. Min Max Problem. More room exists for solutions. Linear relation in terms of $\varepsilon_{d e s}$. A minimum point may be searched for $T_{\text {sup }}$, which in fact, is not available from the following simple differentiation of Equation 21

$$
\frac{d \sum \mathrm{CO}_{2}}{d T_{\text {sup }}}=0=\left[-0.87 R \times\left|1-\frac{T_{\text {ref }}}{T_{\text {sup }}}\right|^{-2} \times\left(\frac{T_{r e f}}{T_{\text {sup }}^{2}}\right)\right]\{\text { No minimum }\}
$$

\section{RESULTS}

The original equations were derived in this research by the Author (Except Eq. 1, which represents the very well-known 1st Law efficiency), based on our references $[11,12,14,16,21]$ and presented above, were used to determine the relationship between the operating (supply) temperatures in the built environment and the $\mathrm{CO}_{2}$ emissions, including the embodied emissions in district energy systems, which are gaining popularity for achieving the targets of decarbonization with total electrification. Exergy destructions play an important role in total $\Sigma \mathrm{CO}_{2}$ emissions, which includes the nearly-avoidable emissions, $\mathrm{CO}_{2}$, as a result of exergy destructions. Fig. 6 shows the variation of $\Sigma \mathrm{CO}_{2}$ emissions concerning the supply temperature, Tsup in the built environment by assuming a constant $1{ }^{\text {st }}$ Law efficiency in all sectors, namely 0.8 , on average. In this figure, Eq. 18 is used. There are seven cases. The first case, referring to the 1st Law only (Eq. 1), is for a solar system without fossil fuels. Because this case ignores exergy destructions even without embodiments included, it falsely implies that solar systems have zero emissions. The second case is the base case for fossil 
fuels, which also refers only to the $1^{\text {st }}$ Law, which represents the use of natural gas in a boiler with an efficiency of 0.8 . This case falsely indicates the lowest total emissions, irrespective of the amount of exergy destructions and the level of the supply temperature. It assumes that the efficiency is constant with the supply temperature and does not care about exergy destructions (Insensitive to R). In all remaining cases, the $2^{\text {nd }}$ Law-related nearly-avoidable emissions are included (Eq.18). The third case with the lowest emissions is a solar PVT system, generating both power and heat from solar energy. The exergy destruction is minimal, which corresponds to an R-value of only 0.25 . Beginning from this case, all remaining cases are sensitive to $\mathrm{R}$ and the supply temperature, making much sense. The remaining cases compare renewables and natural gas (NG) fossil fuel-based applications, like a boiler and a power generator. The maximum $\Sigma \mathrm{CO}_{2}$ occurs in an NG boiler. $\Sigma \mathrm{CO}_{2}$ in all cases, except the first and the second cases, decrease with an increase in supply temperature, which contradicts the hypothesis that lower temperatures are desirable for utilizing low-enthalpy renewables and waste heat in any case. For example, to keep the power generation efficiency of a solar PVT panel at its rated value in hot climates, the supply water temperature must be kept minimum for effective cooling of the PV panels. However, this condition calls for slightly increased emissions. Therefore an optimum supply temperature may be determined by comparing the loss in efficiency of the PV panels versus the decrease of $\Sigma \mathrm{CO}_{2}$ at a slightly higher supply temperature permitted in the hydronic circuit of the PVT panel. The next application with higher emissions responsibility is solar PV with an R-value of 0.5. The following case is solar FPC with $R=0.75$. The last two cases compare fossil fuels, which have the highest emissions, as expected. This figure also notes that the dependence of $\Sigma \mathrm{CO}_{2}$ on Tsup gets sharper with an increase in R. With all this useful information provided by Fig. 6, something seems to be missing, which indicates that emissions decrease with higher supply temperatures, which defeats the hypothesis mentioned above. Therefore, in this research, for more comprehension of the subject matter, Fig. 7-a was prepared. Now, Fig. 7-a shows that exergy efficiency, $\eta_{\text {II }}$, decreases with higher temperatures, while supply exergy increases $\left(\mathrm{T}_{\text {sup }}\right)$, and there is an optimum supply temperature for minimum emissions.

For example, the exergy efficiency, $\eta_{I I}$, decreases from 0.7 at $T_{\text {sup }}$ of $310 \mathrm{~K}$ to less than 0.3 at

$T_{\text {sup }}=365 \mathrm{~K}$. This is an almost $60 \%$ decrease in the $2^{\text {nd }}$ Law efficiency, while Fig. 6 assumes that the $1^{\text {st }}$ Law efficiency is not sensitive to the entire range of $T_{\text {sup }}$ shown in these figures. The trend of $\eta_{I I}$ shown in Fig 7-a may be extrapolated to $\Delta \mathrm{CO}_{2}$ emissions responsibility because they are related:

$$
\begin{aligned}
& \Delta C O_{2}=0.27\left(1-\varepsilon_{\text {sup }} \cdot \eta_{I I}\right)(\text { Case } 1 \text { in Figure } 4) \\
& \Delta C O_{2}=0.63\left(1-\varepsilon_{\text {sup }} \cdot \eta_{I I}\right)(\text { Case } 2 \text { in Figure } 4)
\end{aligned}
$$

According to the above relationships, $\Delta \mathrm{CO}_{2}$ increases at higher temperatures where $\eta_{I I}$ decreases if $\varepsilon_{\text {sup }}$ is constant (same energy source). It is also interesting to note that it matters whether part of the supply exergy is destroyed before the useful application (Case 2) or exergy is destroyed after the useful application (Case 1). Therefore, the way input exergy is utilized and destroyed is important to follow, which can only be facilitated by the $2^{\text {nd }}$ Law. 


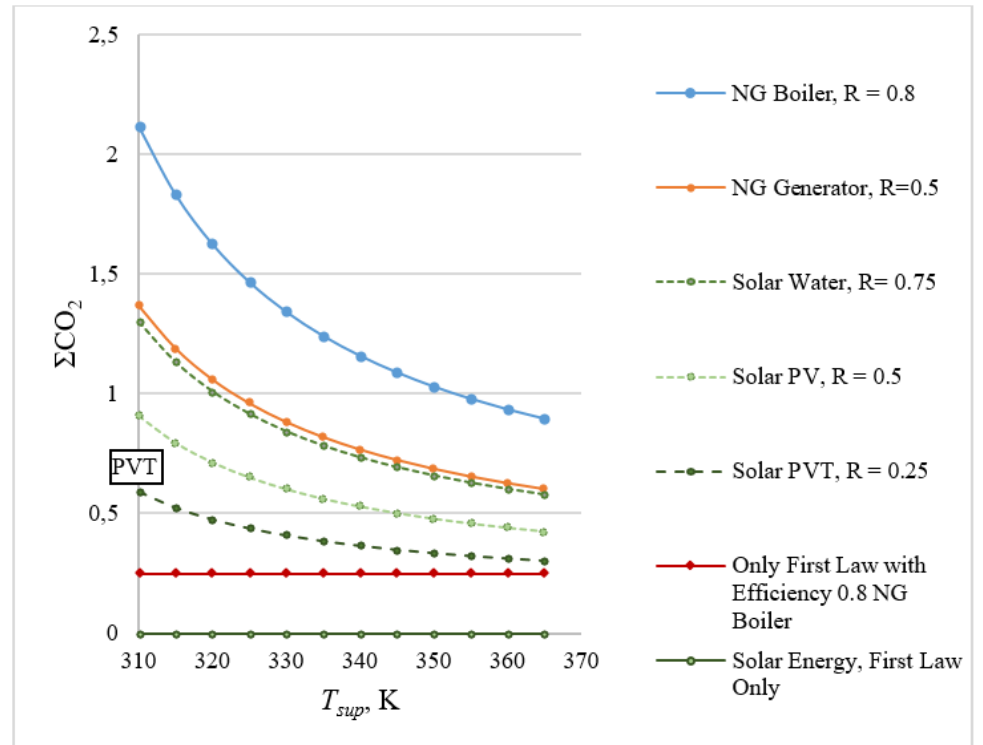

Figure 6. Total $\mathrm{CO}_{2}$ Emissions with Supply Temperatures. For a constant 1st Law efficiency of 0.8

Even further, the unit exergy supply, $\varepsilon_{\text {sup }}$, is important. Low-temperature renewable and waste heat sources, for example, have low $\varepsilon_{\text {sup }}$. For solar energy insolation level of $750 \mathrm{~W} / \mathrm{m}^{2}$ impingent on a solar panel surface, $\varepsilon_{\text {sup }}$ is $0.52 \mathrm{~kW} / \mathrm{kW}$ [11]. For a fossil fuel like natural gas, $\varepsilon_{\text {sup }}$ is $0.87 \mathrm{~kW} / \mathrm{kW}$.

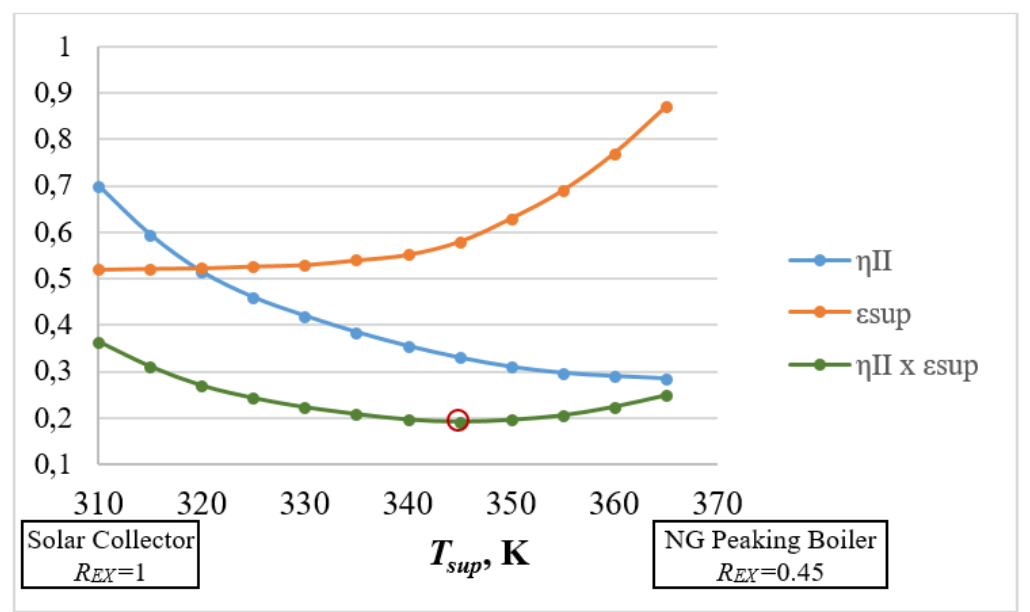

Figure 7-a. Exergy Efficiency Decrease with Supply Temperature.

Therefore, this time $\Delta \mathrm{CO}_{2}$ increases with low-temperature sources. However, the product of $\varepsilon_{s u p}$ and $\eta_{I I}$ has a minimum $T_{\text {sup }}$ value in favor of low-temperature applications. This condition is another indication that a $100 \%$ renewable scenario is not possible because some higher unit exergy sources may be necessary to be mixed to low-temperature energy sources for minimum emissions. In Fig. 7, this minimum point corresponds to a supply temperature of $345 \mathrm{~K}\left(72^{\circ} \mathrm{C}\right)$. At low solar insolation levels, such a temperature may be difficult to obtain from a solar flat-plate collector, especially in PVT systems. This condition requires some temperature peaking, probably by mixing some fossil fuels. This result needs to be further revised because Fig. 7 includes only the $\Delta \mathrm{CO}_{2}$ term, representing exergy destructions. The introduction of fossil fuels means direct $\mathrm{CO}_{2}$ emissions. Then:

$$
\begin{aligned}
& \Delta C O_{2}=0.27\left(1-\varepsilon_{\text {sup }} \cdot \eta_{I I}\right)+\left(1-R_{E X}\right) \frac{c_{K}}{\eta_{B}}(\text { Case } 1 \text { in Figure 4) } \\
& \Delta C O_{2}=0.63\left(1-\varepsilon_{\text {sup }} \cdot \eta_{I I}\right)+\left(1-R_{E X}\right) \frac{c_{K}}{\eta_{B}}(\text { Case } 2 \text { in Figure 4) }
\end{aligned}
$$


The next revision transforms Fig. 7-a to Fig. 7-b, showing that the $1^{\text {st }}$ and $2^{\text {nd }}$ Laws are essential in evaluating and planning any decarbonization measure. Fig. 7-b shows that total decarbonization may be theoretically achieved if embodiments carried by renewable systems and equipment are ignored. Nevertheless, the question of whether the $2^{\text {nd }}$ Law comes first is not answered yet.

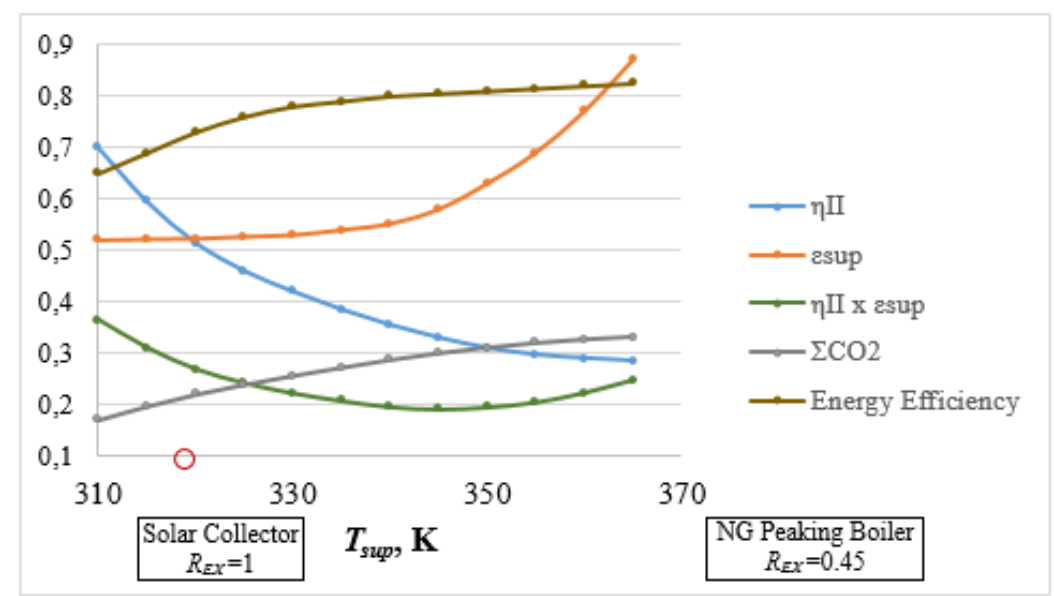

Figure 7-b. Minimum $\Sigma \mathrm{CO}_{2}$ Occurs with the Lowest Possible Supply Temperature

Fig. 8 shows that exergy destructions may be minimized only at lower temperatures and more sensitive to the supply temperature than $1^{\text {st }}$ Law efficiency: Fig. 7-b shows that the $2^{\text {nd }}$ Law efficiency is more sensitive to the supply temperature than the $1^{\text {st }}$ Law. Therefore also taking direct $\mathrm{CO}_{2}$ emissions according to the $1^{\text {st }} \mathrm{Law}, 2^{\text {nd }} \mathrm{Law}$ in decarbonization comes first.

\section{Exergy Destruction, $\mathrm{kW} / \mathrm{kW}$}

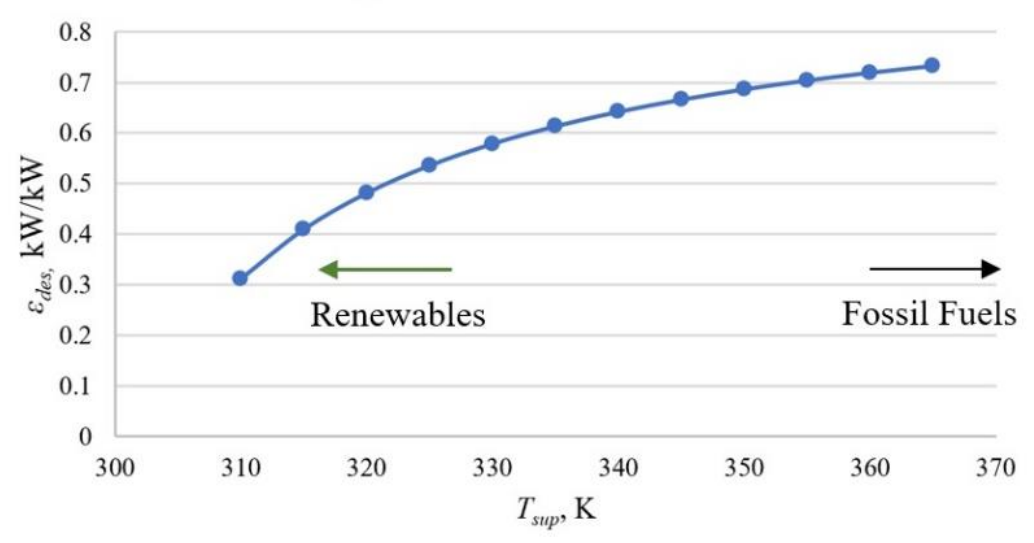

Figure 8. Exergy Destructions Increase with Supply Temperature

When Fig. 7-a is overlaid on to Fig. 6, the correct solution, which acknowledges that exergy destructions come first in solutions for sustainable measures for climate emergency, on the other hand, by increasing the main loop pipe diameter in a district energy system, the pumping power (Thus running costs) are fixed. However, the lower the supply temperature is, the higher the $\mathrm{CO}_{2}$ embodiments in a district energy system. Therefore, Low and Ultra-Low temperature applications are realistically justified with this graph in typical thermal applications. Even when embodiments are considered, Fig. 9 shows that total emissions responsibility decreases at low application temperatures. Therefore, Low and Ultra-Low temperature applications are realistically justified with this graph in typical thermal applications. Fig. 9 confirms Fig. 7-b, even when the embodiments of the district piping are included. 


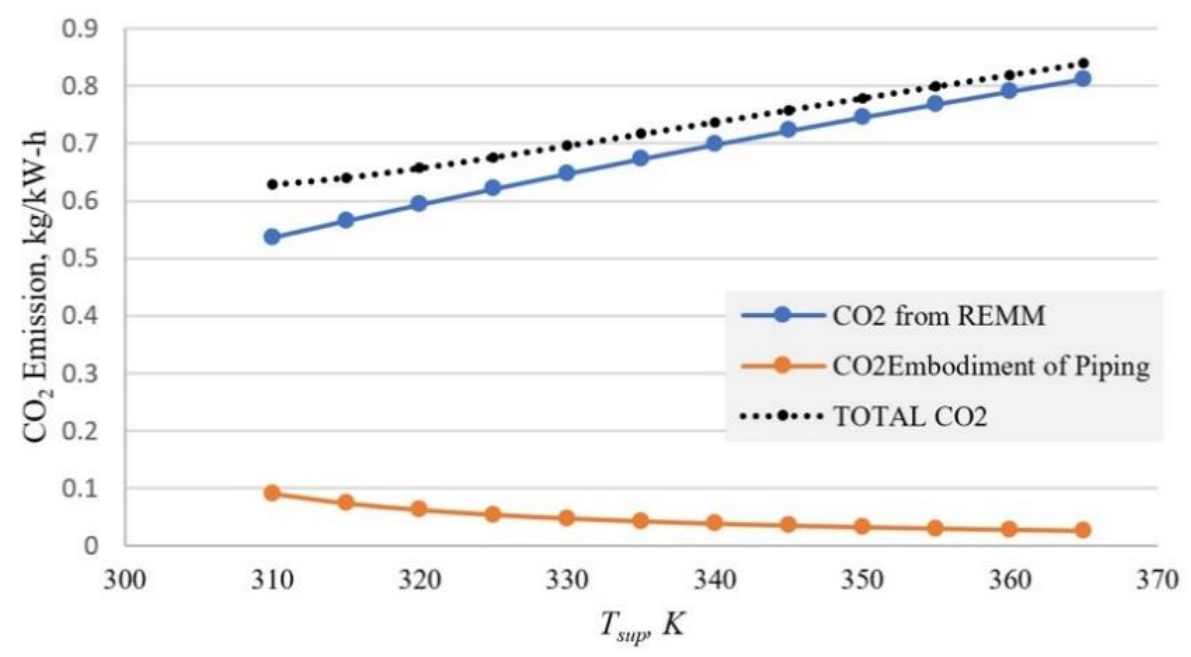

Figure 9. Exergy-Based Sustainable Environment Conditions

\section{CONCLUSIONS}

This paper answers whether energy efficiency comes first or the exergy destructions issue comes first in implementing a complete set of measures for reducing global warming in the context of climate emergency. Fig. 10 shows that the Paris Agreement goal may be reached only with exergy-based solutions as well as increasing the $R_{E X}$ of the energy mix, low-temperature harvesting of solar, lowenthalpy geothermal, and waste heat which are abundantly available all over the World. However, until now, their positive impact was not recognized, which is only visible with the exergy destruction minimization.

Results show that a 30 percent-point decrease of exergy destructions comparing to the supplied exergy in the thermo-mechanical system reduces total $\mathrm{CO}_{2}$ emissions by $35 \%$. The paper argues that current exergy destruction is around 0.8 of the supply exergy, as an industry average, which gives ample room for improvement using the $2^{\text {nd }}$ Law, while the $1^{\text {st }}$ Law efficiency is already higher, and there is less room available for improvements concerning $\mathrm{CO}_{2}$ emissions. The paper shows that the $1^{\text {st }}$ Law efficiency may be increased by about 0.15 points, which gives a window of opportunity about a 25 percent-point decrease in emissions (Figures 6,7-a, and 7-b).

It is understood that when we recognize the importance of the rationality factor, which is the missing link so far, the targets of the Paris agreement will not be reached. Now, this link is included in Fig. 10. According to Fig. 10, the carbon-neutral target for 2050, based on simple emission calculations, will be missed by about $0.6 \mathrm{~kg} \mathrm{CO}_{2} / \mathrm{kW}$-h in the best scenario of today`s strategies. In 2060, the Paris Agreement goal will also be missed by about $0.3 \mathrm{~kg} \mathrm{CO}_{2} / \mathrm{kW}-\mathrm{h}$. Even worse, a $30 \%$ renewable target of around 2025 will stay above the requirements for reducing climate crisis and remain there unless all nations abandon the recent natural gas craze and insistence on coal. Generating hydrogen from coal will not a solution either, and it will stay at a high emissions point if the hydrocarbon economy continues. Fig. 10 further shows that whatever measures are taken, we will not reach a negative carbon state unless we embrace nature and incorporate it with rational carbon capture methodologies. As a result, all strategists and energy policymakers need to recognize the importance of the rationality factor in all applications. Then new methodologies, new equipment, buildings, machinery, and performance metrics need to be developed to rate these applications towards truly minimum $\mathrm{CO}_{2}$ emissions responsibilities, which have a definite effect on global warming. In this quest, the goal must be to minimize useful work potential (exergy) destructions. 


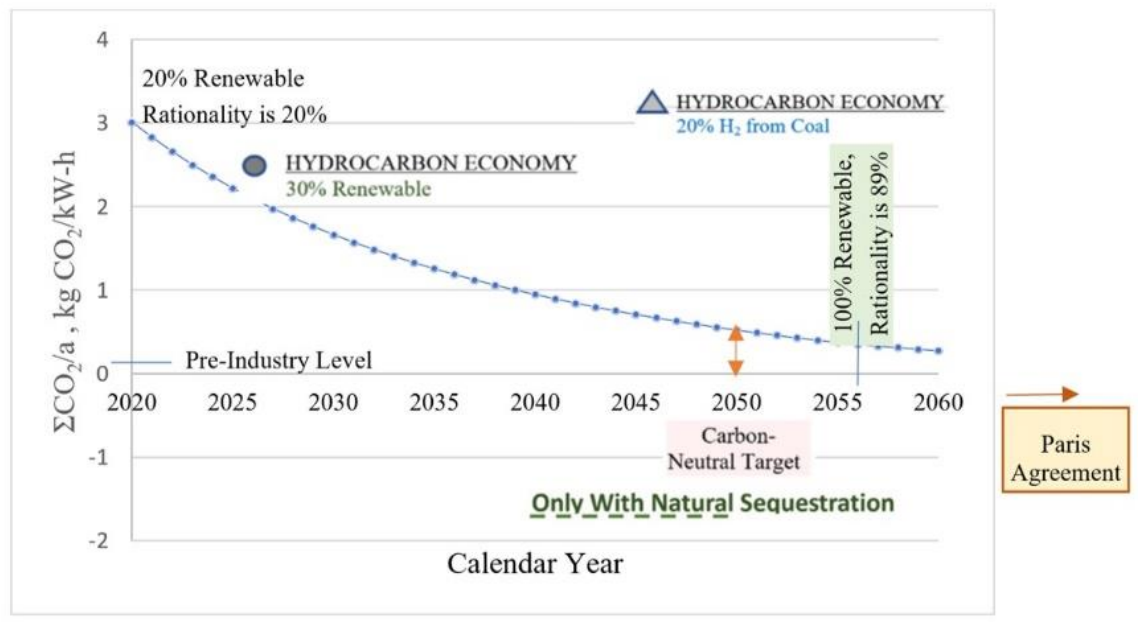

Figure 10. Total Global $\mathrm{CO}_{2}$ Emissions per Year, $\mathrm{kg} \mathrm{CO} / \mathrm{kW}-\mathrm{h}$

As a final remark, it must be kept in mind that the $2^{\text {nd }}$ Law enforces challenges for sustainable decarbonization, such that the 1st Law may never realize them. Consider a simple heat pump case used for comfort cooling. According to the $1^{\text {st }} \mathrm{Law}$, the standard COP definition for a heat pump is a simple function of the $\Delta T_{o}$ across the heat pump. It is insensitive to $T_{\text {out }}$ and $T_{\text {in }}$ temperature levels. In other words, $C O P$ does not change as long as the $\Delta T_{o}\left(T_{\text {in }}-T_{\text {out }}\right)$ is the same irrespective of the absolute values of $T_{\text {out }}$ and $T_{\text {in }}$. The $1^{\text {st }}$ Law defeats the strategies of decarbonization and sustainability of the built environment and the energy sector because it does not matter whether low-exergy sources, including waste heat, are utilized, or high-exergy fossil fuels are used. The only economy matters as long as the $C O P$ is high enough and $\triangle T$ is maintained the same.

$C O P=a+b\left(\frac{\Delta T_{o}}{n}\right)^{-1}$

$C O P$ seems to be increasing with lower $\Delta T$ in each heat pump by using multiple heat pumps $(n)$ in series. However, to accommodate for $n$ values greater than two, where each $\Delta T$ must be at least $2 \mathrm{~K}$, $\Delta T$ needs to be increased proportionately, which is bounded by indoor comfort requirements. The following rule is applied:

$\Delta T=[5 \mathrm{~K}+(n-1) \times 1.2 \mathrm{~K}] \quad\{\Delta T \geq+2 \mathrm{~K}\}$

The major flaw of the $1^{\text {st }}$ Law is that it does not consider the large unit exergy difference between the electric power demand $(0.95 \mathrm{~kW} / \mathrm{kW})$ that the heat pump requires and the unit cold exergy that it supplies for comfort cooling. This exergy destruction occurs irrespective of where and how the electric power is generated. The same condition holds if a building generates its power from rooftop PV panels. This power could be allocated to more rational applications, like mass transportation, rather than spending it for comfort cooling. The unit exergy destruction is in the following amount:

$\varepsilon_{\text {des }}=0.95-\operatorname{COP} \times\left(1-\frac{T_{\text {out }}}{T_{\text {in }}}\right)$

Here, according to the $2^{\text {nd }}$ Law, absolute values of $T_{\text {out }}$ and $T_{\text {in }}$ matter. For zero exergy destruction $\left(\varepsilon_{d e s}=0\right), C O P$ from the above expression must be 54.15 in a standard indoor space application with $7^{\circ} \mathrm{C} / 12^{\circ} \mathrm{C}$ regime. This $C O P$ value is impossible, and there will always exergy destructions, causing $\triangle \mathrm{CO}_{2}$ emissions responsibility (See Equations 6-a and 6-b). The COP value may be increased using two heat pumps in series, which share the $5 \mathrm{~K}$ of $\Delta T_{o}$ equally ( $2.5 \mathrm{~K}$ for each heat pump). Then the $C O P$ value of each heat pump increases from $5.5(n=1, \Delta T=5 \mathrm{~K})$ to $9.06(n=2, \Delta T=2.5 \mathrm{~K})$, if the 
coefficients $a$ and $b$ are 0.5 and $25 \mathrm{~K}^{-1}$, respectively, for a typical heat pump. This value is the upper limit for $C O P$ because, for the higher number of series-connected heat pumps $(n>2), \Delta T$ decreases below $2 \mathrm{~K}$, and it is not economically feasible to have more and smaller heat pumps. Moreover, the series connection reliability, $R_{\text {total }}$ drops according to the $R_{\text {total }}=R_{1} \times R_{2} \times R_{3} \ldots$ reliability rule.

If the reliability is not a concern, and the total $\Delta T$ may be increased from $5 \mathrm{~K}$ to $9.8 \mathrm{~K}, n$ may be increased up to five $(n=5)$, which increases the COP of each heat pump to 15.25 from $9.06(n=2)$. This is still a far lower value for the $\varepsilon_{d e s}=0$ condition. This calculation shows that there is a diminishing return of using more heat pumps in series, which is shown in Fig. 11. To improve the reliability of the heat pump agglomeration, their arrangement may be split into an optimum set of series and parallel connections, but in this case, the overall COP will decrease. This figure shows that $\Delta \mathrm{CO}_{2}$ may be decreased but may never be eliminated in heat pumps, whether electricity comes from renewables or fossil fuels. Of course, in the latter case, there will also be direct $\mathrm{CO}_{2}$ emissions depending upon the fossil fuel consumed and the energy conversion system used.

Then the $2^{\text {nd }}$ Law takes over for better understanding the impossibility of achieving zero carbon cities even with total renewable electrification and by using heat pumps for comfort heating and cooling. This is a typical example where the $1^{\text {st }}$ Law loses its priority at this point.

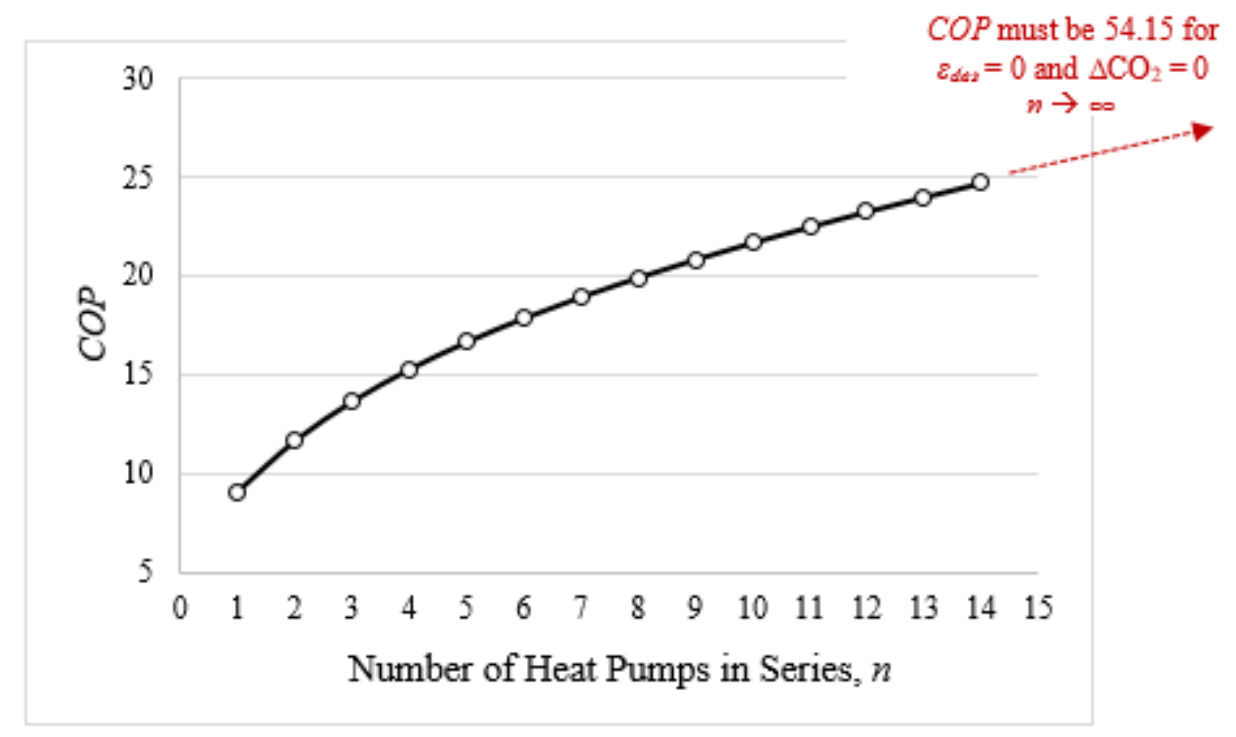

Figure 11. Diminishing Returns of $n$ for increasing COP

The $2^{\text {nd }}$ Law defines an exergy-based $C O P$, which includes the absolute values of the relevant temperatures [11,14].

$\operatorname{COPEX}_{n}=\left[a+b\left(\frac{n}{(3.8+1.2 n)}\right)\right] \times\left(1-\frac{T_{\text {out }}}{\left(T_{\text {out }}+3.8+1.2 n\right)}\right)$

With the given $a$ and $b$ values:

$\operatorname{COPEX}_{n}=\left[0.5+25\left(\frac{n}{(3.8+1.2 n)}\right)\right] \times\left(1-\frac{T_{\text {out }}}{\left(T_{\text {out }}+3.8+1.2 n\right)}\right)$ 


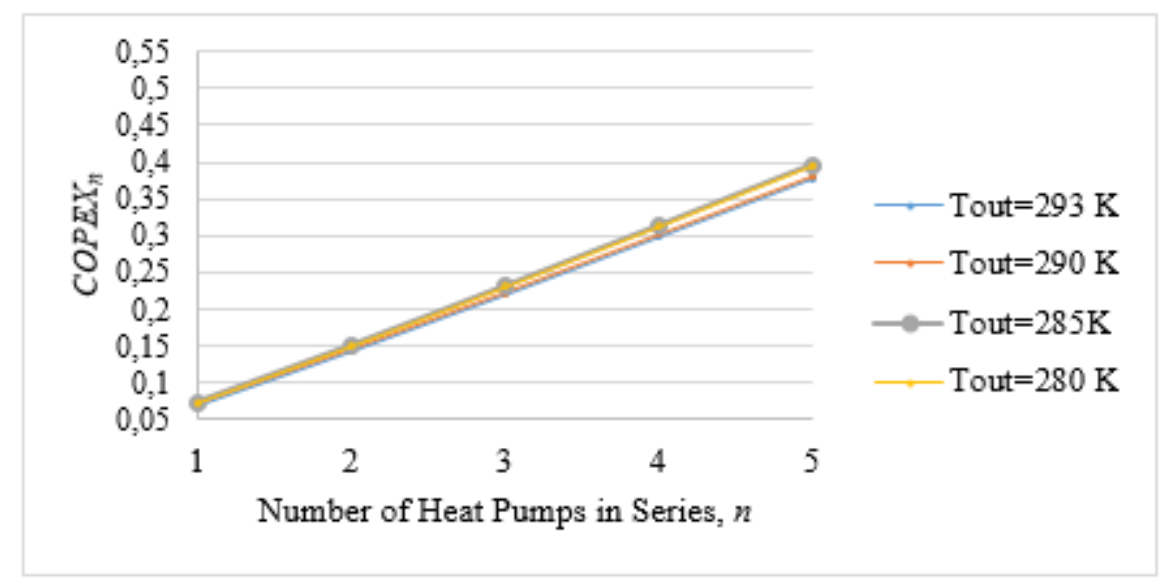

Figure 12. Variation of $\mathrm{COPEX}_{n}$ with $(n)$ and $\left(T_{\text {out }}\right)$

Fig. 12 shows the variation of $C O P E X_{n}$ with $(n)$. COPEX $X_{n}$ increases with (n) but stays almost constant with $T_{\text {out }}$. Thus, the $2^{\text {nd }}$ Law gives almost complete freedom to choose the $T_{\text {out }}$ and $T_{\text {in }}$ depending upon specific design conditions for minimum exergy destructions, with the series arrangement, as economic, physical, and operational conditions permit. This is design flexibility that permits better optimizations of a system. On the other hand, high-temperature cooling is a necessity for LowEx buildings. This case is also achievable with little compromise in $C O P E X_{n}$, because it slightly decreases with $T_{\text {out }}$. The $2^{\text {nd }}$ Law also shows the next challenge for the necessity of developing hightemperature cooling equipment, like heat piped-hybrid wall panels, as shown in Fig. 13-a and 13-b [24]. This system employs both radiant panel technology with natural convection and thermal radiations along with forced convection through the perforated wall surface with a small fan. This system can satisfy sensible cooling loads at $T_{\text {out }}$ vales around $293 \mathrm{~K}$.

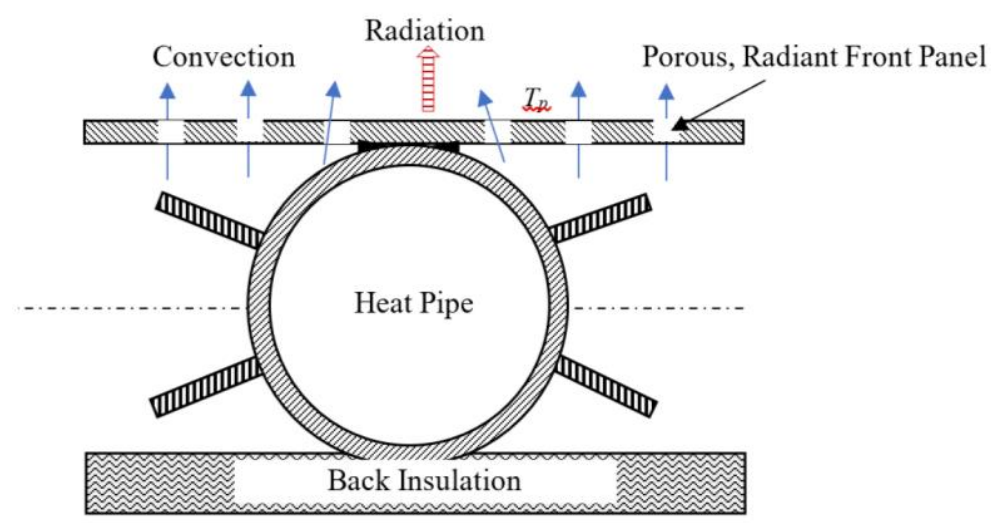

Figure 13-a Sectional Top View of the Radiant Wall Panel

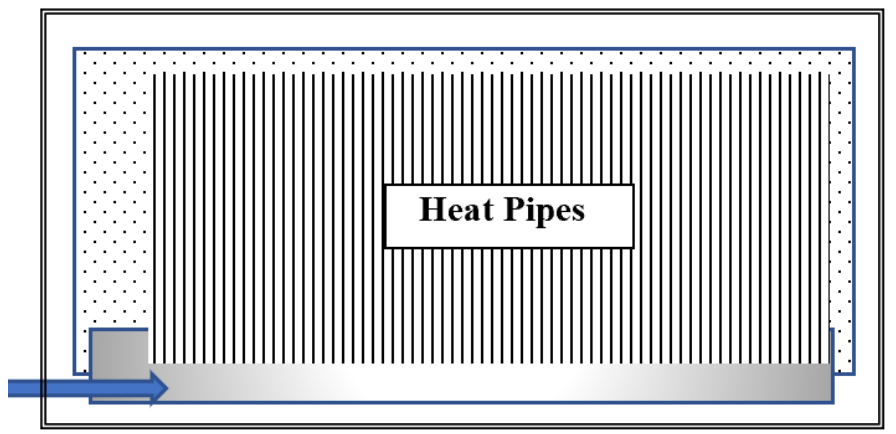

Figure 13-b. Back-Side Cut-Away View of the Heat-Pipe Wall Panel 
In conclusion, the $2^{\text {nd }}$ Law places new challenges and at the same time shows new directions for sustainable solutions and enforces the development of new systems and equipment that were not deemed necessary and possible before. Therefore, this Law is a game-changer and a game maker, and this paper shows that it comes first in future explorations for sustainability and decarbonization.

\section{REFERENCES}

[1] Internet Web-Site: https://www.un.org/sg/en/content/sg/statement/2020-11-19/secretary-generals-remarksclimate-action-european-council-foreign-relations, The secretary-general remarks on climate action to European Council on Foreign Relations, 19 November 2020.

[2] Internet Web-Site: https://www.theguardian.com/environment/2020/dec/12/un-secretary-general-allcountries-declare-climate-emergencies-antonio-guterres-climate-ambition-summit, UN secretary-general urges all countries to declare climate emergencies, 12 December 2020.

[3] Internet Web-Site: https://www.rhc-platform.org/content/uploads/2020/10/RHC-ETIP-SRIA-2020WEB.pdf, Sria for the renewable heating and cooling sector, European Technology and Innovation Platform, 12 April 2021.

[4] Uyar, TS. Accelerating the Transition to a 100\% Renewable Energy Era. Cham, SWITZERLAND: Springer International Publishing, 2020.

[5] Internet Web-Site: https://www.rhc-platform.org/content/uploads/2019/04/RHC_Common_Roadmap.pdf, Common Implementation Roadmap for Renewable Heating and Cooling Technologies European Technology Platform on Renewable Heating and Cooling, RHC Platform, Brussels, 12 April 2020.

[6] Internet Web-Site: ttps://ec.europa.eu/energy/sites/ener/files/energy_system_integration_strategy_.pdf, Powering a climate-neutral economy: An EU Strategy for Energy System Integration, 08 July 2020.

[7] Internet Web-Site: https://eur-lex.europa.eu/legal-content/EN/TXT/?uri=CELEX\%3A52020DC0098, Communication from the commission to the European parliament, the council, the European economic and social committee and the committee of the regions, a new circular economy action plan for a cleaner and more competitive Europe, 11 March 2020.

[8] Internet Web-Site: https://www.scienceeurope.org/media/0vxhcyhu/se_exergy_brochure.pdf, In a resource-constrained world: think exergy, not energy, June 2016.

[9] Thomassen, G, Konstantinos KK, Navarro, JP. The decarbonization of The EU heating sector through electrification: a parametric analysis. Energy Policy 2021; 148(2021):1-17, DOI :10.1016/j.enpol.2020.111929

[10] Internet Web-Site: https://www.rhc-platform.org/content/uploads/2020/10/RHC-ETIP-SRIA-2020WEB.pdf, Strategic research and innovation agenda for climate-neutral heating and cooling in Europe, 10 April 2021.

[11] Kilkis, B. Development of a composite PV panel with PCM embodiment, TEG modules, flat-plate solar collector, and thermally pulsing heat pipes. Solar Energy 2019; 200(2020):89-107. https://doi.org/10.1016/j.solener.2019.10.075

[12] Kilkis, B. Exergy-based hydrogen economy with $100 \%$ on-board renewables, $\mathrm{H}_{2} \mathrm{~S}$ reserves, and coastal hydrogen cities in the black sea region. Ankara, TURKEY: Special Report to Turkish Ministry of Energy and Resources (MENR), 2020.

[13] Internet Web-Site: https://theicct.org/blog/staff/e-fuels-will-not-save-ice, E-fuels Won't save the internal combustion engine, 23 June 2020.

[14] Kilkis, B. Accelerating the Transition to 100\% Renewable Era. But How? Exergy Rationality in the Built Environment. In: Uyar, TS, Editor, Accelerating the transition to a $100 \%$ renewable energy era. Cham, Switzerland: Springer International Publishing, 2020. pp. 1-49, doi.org/10.1007/978-3-030-40738-4.

[15] Falk, PM. Evaluation of district heating systems based on exergy analysis (Ph.D.), Technical University Darmstadt (TTD), Darmstadt, GERMANY, 2018.

[16] Kilkis, B. Sustainability and decarbonization efforts of the EU: Potential Benefits of Joining Energy Quality (Exergy) and Energy Quantity (Energy) in EU Directives, Exclusive Position Report Submitted to EU Presidency (Malta), Ankara, TURKEY: TTMD Report, 2017.

[17] Kerdan, IG, Raslan, R. The role of an exergy-based building stock model for exploration of future decarbonisation scenarios and policy making. Energy Policy 2017; 105: 467-483. https://doi.org/10.1016/j.enpol.2017.03.020.

[18] Internet Web-Site: https://www.eia.gov/totalenergy/data/monthly/archive/00351804.pdf Total energy, US Energy Information Administration, Monthly energy review, Table 2.1, April 2018.

[19] Internet Web-Site: https://www.pwc.com/gx/en/psrc/pdf/world_in_2050_carbon_emissions_psrc.pdf, PricewaterhouseCoopers LLP. The world in 2050 can rapid global growth be reconciled with moving to a low carbon economy?, July 2008. 
[20] WMO. WMO Statement on the status of the global climate in 2006. Geneve, SWITZERLAND: WMO, 2007.

[21] Kılkış, Ş., Kılkış, B. An urbanization algorithm for districts with minimized emissions, based on urban planning and embodied energy towards net-zero exergy targets, Energy 2019;179 (2019):392-406.

[22] Internet Web-Site: https://en.wikipedia.org/wiki/World_energy_consumption, World energy consumption, 10 April 2021.

[23] Internet Web-Site: https://www.worldenergydata.org/world-total-final-consumption/, World total final consumption, 10 April 2021.

[24] Kilkis, B. Lessons learned from labyrinth type of air preconditioning in exergy-aware greenhouses, In: SDEWES 2021 16. Conference on Sustainable Development of Energy, Water and Environment Systems; 10-15 October 2021: (Accepted). 